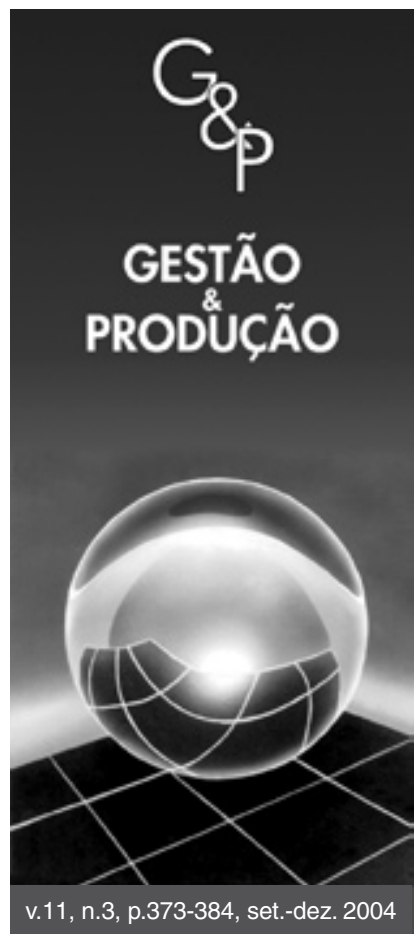

\title{
ANALISANDO A RECONFIGURAÇÃO DA CADEIA DE PRODUÇÃO DE PNEUS NO BRASIL PELA ECONOMIA DOS CUSTOS DE TRANSAÇÃO
}

\author{
Sandro Cabral \\ Núcleo de Pós-Graduação em Administração, NPGA, \\ Universidade Federal da Bahia, UFBA, \\ Rua Augusto F. Schmith, 156-D/404, CEP 40140-390,Barra, Salvador, BA, \\ e-mail: sandro.cabral@uol.com.br
}

Resumo

Utilizando um estudo de caso como recurso metodológico, este trabalho discute o processo de reconfiguração da cadeia de produção de pneus no Brasil, a partir da pioneira terceirização/desintegração vertical de um processo industrial de elevada criticidade, envolvendo a relação contratual estabelecida por duas grandes corporações multinacionais atuantes na cadeia. São realizadas análises sobre o processo de adaptação contratual e as razões que contribuíram para o retardamento das decisões de reestruturação da cadeia no Brasil, visto que situação similar já ocorria na Europa desde meados da década de 80. A Economia dos Custos de Transação (ECT) é utilizada como arcabouço teórico principal nas discussões do presente trabalho, principalmente, em função de sua capacidade analítica sobre os limites de atuação de uma firma ou de uma rede organizacional.

As principais conclusões apontam para a importância de fornecedores locais especializados e, por conseqüência, de ações estratégicas à sua atração, como fatores críticos à viabilização da reconfiguração da cadeia via terceirização de processos industriais, sobretudo quando ativos específicos estão envolvidos. O ambiente institucional, formal e informal, mostra-se igualmente relevante, tanto para o processo de execução contratual em si quanto para a tomada de decisões necessárias à definição das novas fronteiras organizacionais.

Palavras-chave: gestão da cadeia de suprimentos, terceirização, custos de transação, especificidade de ativos, ambiente institucional.

\section{Introdução}

As novas demandas estruturais e conjunturais pressionaram as empresas industriais a repensarem suas condutas, como forma de obterem um desempenho adequado aos atuais padrões de competitividade. Em meio ao turbulento cenário dos últimos anos, tem sido largamente propalado, como uma espécie de mantra corporativo, que reduzir custos fixos, promover a focalização da organização sobre sua atividade fim e operar de forma otimizada ao longo de toda a cadeia de produção, constituem-se fatores imperativos para a própria sobrevivência das organizações.
Dentro deste contexto, a terceirização, “...tem se apresentado como uma possibilidade adequada para uma série de situações enfrentadas pelas empresas brasileiras" (Rezende, 1997, p.11), contribuindo decisivamente para o sucesso, e não raro, para o fracasso, de processos de reconfiguração das cadeias de suprimento.

Independentemente do resultado obtido, se primeiramente os esforços terceirizantes alcançaram maciçamente os processos satélites da organização, tais como: vigilância e limpeza, se percebem, atualmente, movimentos mais abrangentes deste fenômeno em direção a funções, até então, consideradas vitais e pertencentes ao seleto 
grupo de atividades ligadas ao core business da organização, como por exemplo: processos de fabricação de componentes vitais ao desempenho do produto final.

Neste sentido, o presente trabalho visa analisar questões relacionadas ao processo de reconfiguração da cadeia de produção de pneus no Brasil, a partir da terceirização/desintegração vertical do processo produtivo de tratamento de tecidos de reforço, conhecido como dipping, tido como altamente crítico, por sua importância tanto para as etapas subseqüentes de produção, quanto para as características do produto final em si (pneu).

Para tanto, sob o ponto de vista metodológico, utiliza-se um estudo de caso exploratório envolvendo duas organizações: uma fabricante de pneus (que promoveu a terceirização) e uma produtora de tecidos de reforço para a indústria pneumática (que executou a integração vertical). As duas empresas são multinacionais com subsidiárias locais.

Enfatizam-se nesta análise questões relacionadas à adaptação contratual, salientando-se peculiaridades, idiossincrasias e problemas no relacionamento entre as partes envolvidas, ex-ante e ex-post, como forma de se obter um panorama real de como um processo de reconfiguração da cadeia se materializa. Pelo fato da terceirização do processo em estudo ter sido executada no Brasil com um atraso de uma década e meia, em relação a outras unidades do mesmo fabricante de pneus situadas na Europa, serão também tecidas algumas considerações relacionadas às possíveis razões desta defasagem, a qual contribuiu diretamente para o adiamento de decisões envolvendo a reestruturação da cadeia de produção.

Como referencial analítico de suporte, escolheu-se a Economia dos Custos de Transação (ECT), campo teórico construído com o objetivo de lidar com as diferentes formas possíveis de estruturas de governança (mercado, formas contratuais híbridas e hierarquia). Por meio de conceitos-chave como: custos de transação, instituições e especificidade de ativos, a ECT pode contribuir para a determinação do grau de coordenação vertical ideal de uma determinada atividade e, por conseguinte, para os limites de atuação de uma firma ou de uma rede organizacional. Desta forma, uma contribuição adicional deste artigo reside na demonstração das potencialidades analíticas deste referencial em questões pertinentes à realidade empresarial, por meio de sua aplicação em um caso real.

A próxima seção realiza uma breve explanação acerca do conceito de terceirização e suas nuanças. Em seguida, apresenta-se a Economia dos Custos de Transação, incluindo suas origens, pressupostos e dimensões analíticas. Tal exposição, talvez desnecessária àqueles já familiarizados com esta corrente teórica, faz-se útil, sobretudo, àqueles que porventura desconheçam aspectos ligados à sua gênese, seu conteúdo e ao seu jargão.
Na seqüência discute-se o caso empírico em si. Devese salientar que as respostas e conclusões obtidas neste artigo são seguras apenas dentro do contexto analisado, em outras palavras, os resultados efetivos somente se aplicam ao caso estudado. Apenas hipoteticamente, os produtos resultantes deste trabalho poderão ser extrapolados para outras situações dentro do próprio setor focalizado ou para outros setores econômicos.

\section{Terceirização: uma breve visão}

A origem da expressão terceirização remonta ao termo em inglês outsourcing, que significa suprir-se via fontes externas, representando a decisão da organização no sentido de utilizar transações de mercado, em vez da utilização de transações internas, para atingir seus propósitos econômicos.

Representando um processo de revisão das fronteiras organizacionais, a questão da terceirização, segundo Gutwald (1996) pode ser encarada sob três perspectivas distintas: a) análise econômica; b) análise de competências essenciais; e c) análise dos custos de transação.

Embora não abordado diretamente por Gutwald (1996), as organizações, notadamente as empresas industriais, também se valem da terceirização visando à obtenção de melhorias em sua eficiência operacional, sobretudo, no que tange ao aumento da flexibilidade na produção e a possibilidade de acesso às melhores tecnologias disponíveis. A Tabela 1 demonstra alguns benefícios esperados pelas organizações a partir da adoção da terceirização, sob as quatro perspectivas acima comentadas.

Apesar das diversas vantagens, alguns outros aspectos podem inibir o processo de terceirização, como por exemplo: a dificuldade em estabelecer parcerias, dependência do fornecedor, possibilidade de redução da diferenciação e questões sindicais (Rezende, 1997). Desta forma, ainda

Tabela 1. Alguns benefícios decorrentes da terceirização. Fonte: Adaptado de CABRAL (2002).

\begin{tabular}{ll}
\hline Perspectiva & Fatores Estimuladores \\
\hline Econômica Contábil & $\begin{array}{l}\text { Transformação de Custos Fixos } \\
\text { em Variáveis } \\
\text { Disponibilização de recursos } \\
\text { financeiros }\end{array}$ \\
Foco sobre a atividade-fim da \\
empresa \\
Eficiência Operacional & $\begin{array}{l}\text { Maior flexibilidade de produção } \\
\text { Acesso às melhores tecnologias } \\
\text { disponíveis } \\
\text { Melhor eficiência por meio da } \\
\text { Custos de Transação }\end{array}$ \\
& $\begin{array}{l}\text { escolha da forma organizacional } \\
\text { adequada à redução dos custos de } \\
\text { transação }\end{array}$ \\
\hline
\end{tabular}


que a intenção estratégica da organização seja a focalização de seus recursos em atividades ligadas às suas competências essenciais, processos de outsourcing podem ser inviabilizados pela inexistência de um parceiro confiável e tecnologicamente capaz de atender aos critérios de fornecimento estabelecidos.

O caso analisado aqui envolve duas organizações multinacionais, sediadas em países centrais, com operações no Brasil. Para um estudo mais aprofundado sobre o processo de reconfiguração da cadeia na indústria de pneus - a partir de uma transação em particular da cadeia - outros tópicos devem ser incorporados à análise da relação estudada, tais como: imperfeições contratuais; ambiente institucional; incentivos à cooperação mútua; aspectos relacionados a eventuais condutas oportunistas entre as partes; incerteza ambiental; e caráter específico dos investimentos em ativos (Williamson, 2004; Shirley, 2003).

Abre-se, assim, o espaço para uma breve explanação, feita adiante, sobre a abordagem da Economia dos Custos de Transação (ECT). Tendo a transação como sua unidade de análise, a ECT opera em um ambiente de racionalidade limitada, caracterizado pela incerteza e pela informação imperfeita. Destas duas características decorrem custos de transação, cuja tentativa de minimização vai explicar os diferentes arranjos contratuais que cumprem a finalidade de coordenar as transações econômicas de maneira eficiente (Farina et al., 1997).

\section{Economia dos custos de transação}

A Economia dos Custos de Transação (ECT) faz parte da corrente de pesquisa conhecida como Nova Economia das Instituições (NEI), escola do pensamento econômico contemporâneo, focada na análise das variáveis institucionais, transacionais e organizacionais que compõem o universo de atuação das organizações. A NEI parte do pressuposto que as instituições fazem a diferença e são suscetíveis de análise, à medida que reduzem as incertezas, moldando as interações entre os indivíduos, impondo restrições formais - leis, direitos de propriedade -, ou informais - fundamentada em fatores como códigos de ética e/ou tabus. (North, 1990, 2000).

Coase (1937) iniciou a pavimentação da ECT, ao explicar a gênese das firmas, argumentando que se elas podem realizar internamente as mesmas funções que os mercados, podem também ser consideradas como uma via alternativa, em termos de coordenação da atividade econômica, à já estudada via de mercado (Williamson, 1985). A utilização de um ou outro mecanismo de coordenação seria, de acordo com Coase, determinada em função dos custos envolvidos no processamento das transações. Tais custos, de natureza distinta dos custos de produção, foram denominados como custos de transação, os quais também podem ser definidos como: "os custos ex-ante de esboçar, negociar e salvaguardar um acordo, e, sobretudo, os custos ex-post decorrentes de problemas de adaptação que surgem quando a execução de um contrato é imprecisa como resultado de atrasos, erros ou omissões" (Azevedo, 1996, p. 221), incluindo também os custos associados a monitoramento e enforcement de ativos compartilhados (Allen e Lueck, 2004). A ECT é balizada por dois pressupostos comportamentais básicos - racionalidade limitada e oportunismo. Em contraposição à visão dos economistas neoclássicos, o ponto de partida para a existência de custos de transação passa pelo reconhecimento de que os agentes econômicos são racionais - porém limitadamente - e também oportunistas, normalmente agindo de forma auto-interessada (Farina et al., 1997).

A partir das contribuições seminais de diversos autores, as quais foram consolidadas, sobretudo, por Williamson (1985), surgiram os três atributos observáveis da Economia dos Custos de Transação - freqüência, incerteza e especificidade de ativos -, os quais permitem mensurar e inferir os custos em diferentes tipos de transações, contribuindo para a determinação do grau de integração vertical em uma determinada atividade econômica.

Das três dimensões apresentadas, os ativos específicos, "aqueles que não podem ser facilmente reempregáveis, a não ser com perdas de valor" (Williamson, 1985, p. 54), constituem-se como determinantes para a predição de alguns fenômenos analisados sob a ótica da ECT. Implicações adicionais em relação ao efeito de ativos específicos sobre as transações econômicas podem ser observadas por meio da distinção dos diferentes níveis de especificidade de ativos. Williamson (1991) discrimina as ramificações de ativos específicos que contribuem fortemente para o aumento dos custos contratuais:

- especificidade locacional - quando a proximidade entre elos da mesma cadeia produtiva contribui para a diminuição dos custos de transporte e inventário;

- especificidade de ativos físicos - diz respeito às instalações especializadas necessárias à produção de um componente;

- especificidade de ativos humanos - ligado aos recursos humanos necessários à execução de algum processo em particular;

- especificidade de marca - ligada à imagem que a marca de uma empresa possui no mercado;

- especificidade de ativos dedicados - relacionado à necessidade de investimento para transacionar com um cliente/fornecedor em particular; e

- especificidade temporal - ligada à transação que, por 
motivos tecnológicos, tem no tempo um fator crítico.

Dentre os possíveis fenômenos passíveis de análise, por meio do exame da dimensão especificidade de ativos, destaca-se a escolha de configurações organizacionais eficientes que minimizem os custos de transação, conforme o modelo de Williamson (1996), em que a especificidade de ativos é a variável-chave para a minimização dos custos de transação, juntamente com outros parâmetros de deslocamento como ambiente institucional, oportunismo e incerteza, conforme pode ser observado na Figura 1 adiante.

Resumidamente, mantendo-se os parâmetros de deslocamento constantes, ou assumindo as "regras do jogo" como dadas e comuns às diferentes transações analisadas, na presença de níveis de baixa especificidade de ativos, o mercado é a forma mais eficiente, ou seja, a que minimiza os custos de transação. À medida que os níveis de especificidade de ativos crescem, a simples coordenação via sistema de preços passa a não ser a forma mais eficiente, uma vez que os custos de monitoramento e gestão das transações aumentam, abrindo-se, assim, espaço para as configurações contratuais híbridas e/ou hierárquicas (integração vertical). Naturalmente, os parâmetros de deslocamento podem alterar as soluções ótimas das curvas, deslocando os níveis limite de $k$ (especificidade de ativos) para as três formas organizacionais (Farina e Zylbersztajn, 1995), como por exemplo, diminuindo os níveis de especificidade de ativos, mediante a introdução de instituições que garantam a transparência e regulem as condutas dos indivíduos.

Uma vez admitido que as dinâmicas de organização e reestruturação ocorrem, ou ao menos deveriam, na direção de estruturas de governança eficientes, ou seja, de es-

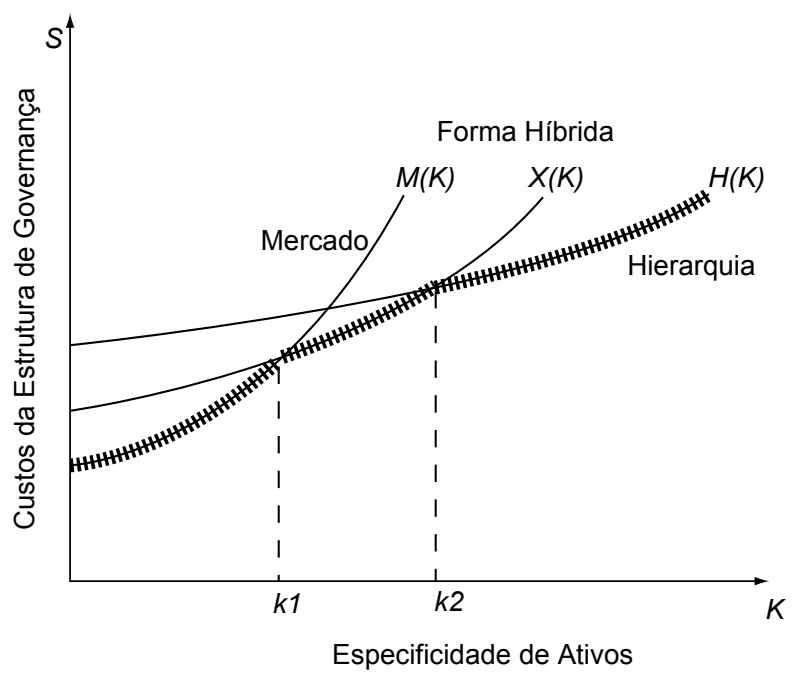

Figura 1. Custos da Estrutura de Governança como função da especificidade de ativos. Fonte: Williamson (1996). truturas que diminuam a exposição das organizações aos riscos associados a uma relação econômica, em uma primeira análise, poderia-se induzir como relevante o papel das matrizes institucionais nas decisões de investimento e no desempenho contratual, sobretudo quando estão envolvidos atores sediados em países centrais, habituados com marcos legais mais aprimorados à proteção contra condutas oportunistas.

À situação acima devem ser consideradas, também, questões envolvendo investimentos em ativos específicos, uma vez que "a parte que arca com estes investimentos fica em uma posição especialmente sujeita a alguma ação oportunista das demais partes" (Azevedo, 1996, p. 17). Além disso, processos de reconfiguração da cadeia de suprimentos com presença de especificidade de ativos, valendo-se da via da terceirização, podem trazer consigo a marca da dependência bilateral, uma vez que tanto o fornecedor, que realiza os investimentos para assumir a atividade, quanto o cliente, que necessita daquele insumo para a continuidade de suas etapas subsequientes de produção, tornam-se vulneráveis a eventuais condutas oportunistas e às variações no ambiente. Logo, a presença de especificidade de ativos pode-se constituir um fator que contribua tanto para o retardamento de decisões sobre reconfiguração da cadeia quanto para o próprio desempenho contratual em si.

Após a apresentação dos referenciais analíticos de suporte, debate-se nas seções vindouras, as suposições acima levantadas, à luz do caso empírico estudado na cadeia de produção de pneus, envolvendo a mudança da estrutura de governança da forma hierárquica em direção à forma híbrida, por meio da terceirização de um processo industrial de suma relevância na cadeia de produção de pneus. A situação de terceirização/desintegração vertical, aqui analisada, pode ser tipificada dentro de uma estrutura híbrida de governança por abarcar um acordo contratual entre entidades independentes, no qual as partes compartilham informações e cooperam entre si, em meio a um ambiente passível de problemas de coordenação e de assimetria de informações (Ménard, 2004), marcado pela relativa complexidade decorrente das implicações presentes e futuras do acordo contratual celebrado (Barthelemy e Quelin, 2000).

\section{Caso empírico: reconfiguração da ca- deia da produção de pneus}

Dentro da estratégia de pesquisa adotada - um estudo de caso envolvendo duas corporações multinacionais, uma responsável pela terceirização e outra, conseqüentemente, pela integração vertical - nesta seção aprofundase a discussão do caso empírico envolvendo a pioneira terceirização no Brasil do processo industrial de trata- 
mento químico de tecidos de reforço para a indústria de pneus, conhecido como dipping. Tal evento contribuiu decisivamente para o processo de reconfiguração da cadeia de produção da indústria, à medida que as alterações nas características desta transação propiciaram o desencadeamento de mudanças, tanto nas dinâmicas de operação de outras etapas situadas a jusante e a montante da cadeia, quanto nas condutas de outros atores do setor, conforme se observa nas seções seguintes.

\subsection{Método}

O método do estudo de caso permite a análise de fenômenos com maior profundidade dentro de um determinado contexto, sendo adequado ao estudo de situações sob vários ângulos e diferentes perspectivas (Roesch, 1999; 2001). Em geral, o método do estudo de caso também é indicado quando as sentenças "por que" e "como" fazem parte da problemática central de pesquisa, notadamente quando se possui pouco, ou nenhum, controle sobre os eventos. Para tal, os estudos de caso apóiam-se nas mesmas técnicas da análise histórica tradicional, adicionando duas novas fontes de evidências: observação direta e entrevistas sistemáticas, sendo relativamente aderentes ao exame de processos decisórios, programas de implantação de inovações gerenciais e de mudanças organizacionais (Yin, 1994).

Realizada entre janeiro e setembro de 2002, a pesquisa apresentou duas dimensões. Primeiramente realizou-se uma pesquisa de caráter documental, por meio da análise de contratos, atas de reuniões e correspondências, no intuito de colher os elementos relevantes dos fatos que permearam o processo de implementação contratual. Realizou-se, também, uma pesquisa de caráter exploratório-descritivo, na qual os instrumentos preferenciais utilizados na investigação foram questionários semi-estruturados, aplicados por meio de entrevistas junto a dirigentes e executivos das áreas de Operações, Tecnologia, Vendas, Suprimentos e Logística das duas partes envolvidas no processo de reconfiguração da cadeia por meio da terceirização da etapa de dipping.

Optou-se por questões abertas para que o máximo de informações qualitativas pudessem ser colhidas. Em alguns momentos, durante a pesquisa, adotou-se o método de entrevistas em profundidade (Malhorta, 2001), no qual mesmo na existência de um esboço pré-determinado, o fraseado específico e a ordem das perguntas são influenciados pelas respostas prévias dos entrevistados. $\mathrm{Na}$ medida do possível, as mesmas perguntas foram feitas a interlocutores distintos, como forma de comparar as diferentes percepções de cada um dos entrevistados sobre um mesmo tema.

Adicionalmente foram entrevistados, também, representantes de outras indústrias de pneus que ainda não optaram pelo processo de terceirização de suas unidades de dipping no Brasil, possibilitando, assim, a verificação das nuanças do processo decisório de um tema comum a empresas de um mesmo setor.

\subsection{Descrição das empresas e da cadeia da indústria de pneus}

As práticas de fornecimento adotadas pelas montadoras, conhecidas como global sourcing, marcadas por esforços intensos em termos de coordenação da cadeia de valor (Womack e Jones, 1998), relações com fornecedores com cobertura intercontinental, normalmente regidas por contratos globais de abastecimento (Carmo e Hamacher, 2001), também forçaram as empresas de pneus a promover uma série de reestruturações. Observa-se que as indústrias de pneus vêm transmitindo aos seus fornecedores ao longo da cadeia de abastecimento as mesmas demandas pelas quais vem sendo submetidas, "transferindo o ônus das estratégias de competitividade" (Quintão e Carvalho, 2002, p. 3), em igual ou maior magnitude, principalmente àqueles que fornecem componentes com impacto significativo na composição do custo do produto final, a exemplo dos tecidos de reforço. Como conseqüência, fornecedores de tecidos de reforço com capacidade de articulação global, portanto capazes de atender às demandas das indústrias de pneus mundialmente, têm começado a despontar remodelando o formato de relacionamento entre cliente e fornecedor neste segmento.

As interações entre os agentes deixam de ser apenas delimitadas por relações envolvendo negociações por preços, mas também se estendem a aspectos relacionados a investimentos conjuntos, intercâmbios tecnológicos visando ao aprimoramento dos produtos e, por fim, à terceirização de processos industriais, conforme o caso analisado neste artigo, o qual envolve duas grandes empresas: a empresa "P" produtora de pneus de origem européia, presente em 24 países e a empresa "T", fabricante de tecidos de reforço com base de náilon para a indústria de pneus, de origem norte-americana com unidades fabris em sete países espalhados por quatro continentes.

A Figura 2 ilustra, de forma resumida, o processo de fabricação de pneus.

Basicamente, um pneu é constituído por borracha, tecidos de reforço e aço para a armação. O processo de fabricação, além de demandar investimentos em ativos específicos, não é algo trivial. Várias fases são necessárias à confecção do produto final, envolvendo distintas cadeias de abastecimento. Paralelamente ao processo de tratamento da borracha, há uma etapa eminentemente têxtil, normalmente realizada pelas empresas produtoras de tecido de reforço, como a empresa " $T$ ", em que a partir de um polímero sintético (náilon ou poliéster) é fabricado um fio que, em seguida, é convertido em teares, obtendo- 
se como produto um tecido não-tratado. Após a etapa de tecelagem o tecido passa por uma etapa de tratamento químico-mecânico, conhecido como dipping, quando lhe são conferidas propriedades fundamentais ao desempenho do produto final, como por exemplo: capacidade de adesão do tecido de reforço à borracha e aumento da resistência à tração e à fadiga.

Unidades de dipping, não atualizadas sob o ponto de vista tecnológico, dificilmente serão capazes de prover os mecanismos de controle de processo necessários à obtenção da uniformidade requerida pelos novos padrões de competitividade, nos quais as indústrias de pneus estão inseridas. Faz-se necessário, assim, a atualização tecnológica dos ativos, o que, indubitavelmente, consumirá investimentos na ordem de milhões de dólares. Em função dos recursos disponíveis para investimentos serem escassos, sobretudo em ativos específicos, abre-se assim o espaço para a discussão da terceirização do processo de dipping. Convém ressaltar que esta não se constitui na primeira experiência de desintegração vertical vivenciada pelas indústrias de pneus, uma vez que elas, no passado, possuíam estruturas verticalmente integradas, tanto para a produção de borracha, isto é, desde os seringais, quanto para a produção de tecidos de reforço, desde o processo de conversão do fio em tecido de reforço e a conseqüente etapa de tratamento. Na verdade, ainda hoje, há casos de empresas que possuem parte destas cadeias verticalmente integradas, sobretudo nos Estados Unidos no que diz respeito à cadeia de produção do tecido de reforço, fornecendo um indício de que o fenômeno da terceirização

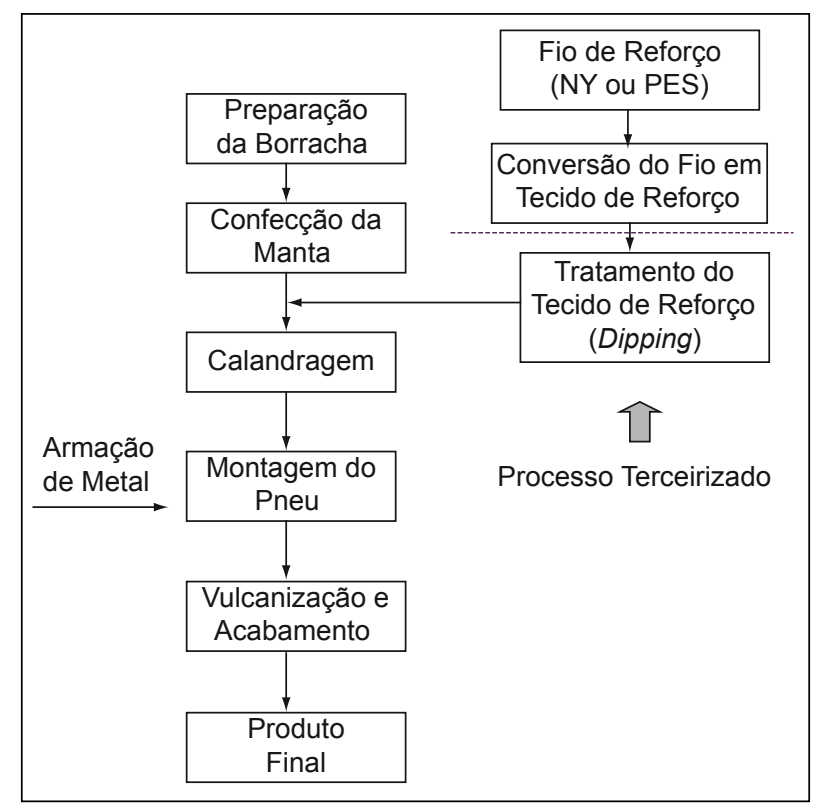

Figura 2. Descrição resumida do processo de fabricação de pneus. Fonte: Elaborada pelo autor. dentro da indústria de pneus não está ligado, necessariamente, ao grau de desenvolvimento do país.

\subsection{Antecedentes do processo de reconfi- guração da cadeia de produção}

A Empresa "P", dentre as grandes empresas transnacionais produtoras de pneus, foi a pioneira na América do Sul a adotar a terceirização em larga escala de suas unidades de dipping na região, a exemplo do que havia sido feito em suas unidades européias há pelo menos quinze anos.

Os principais argumentos favoráveis à terceirização, segundo a empresa "P", estavam associados a maior focalização das atividades no negócio principal (fazer pneus e não tecidos de reforço), possibilidade de atender às demandas mercadológicas em termos de melhoria na qualidade do produto sem a necessidade de investimento em novas tecnologias e um incomum fator: a possibilidade de uso alternativo do terreno onde estava situada uma das unidades de tratamento, localizada em uma área atraente para o negócio de incorporações imobiliárias. Vale ressaltar que investimentos no setor imobiliário fazem parte do rol de atividades exploradas na Europa pela holding controladora da Empresa "P".

No entanto, para alterar a estrutura de governança da transação da hierarquia em direção às formas híbridas ou de mercado, havia a necessidade da existência de fornecedores presentes no mercado sul-americano, capazes de atender aos volumes requeridos pela Empresa "P" dentro dos padrões de qualidade desejados. A este dilema, duas alternativas estariam disponíveis:

a) realizar a transação via mercado junto a fornecedores globais já existentes, com unidades de dipping em outras regiões do planeta (possibilidade esta que se demonstrou inviável, sobretudo, devido ao caráter específico do ativo transacionado e a questões logísticas ligadas às quantidades envolvidas, ao seu transporte em si e à relativa dificuldade de aquisição de produtos via importação, por conta da configuração institucional local); ou

b) procurar atrair fornecedores internacionais de tecido tratado para a América do Sul, utilizando uma forma contratual híbrida, situada entre a integração vertical e a mera utilização do mercado.

Dessa maneira, por volta do ano de 1995, a Empresa "P" iniciou na Europa os primeiros contatos com produtores de tecido de reforço, estimulando-os a investir em unidades de dipping na América do Sul, na tentativa de replicar localmente o modelo de aquisição de tecido tratado, regido sob a estrutura de governança híbrida, iniciado na Europa em meados da década de 80 . Dos pretendentes, sobressaiu-se a Empresa "T" que, além de apresentar um longo histórico de relacionamento com a empresa "P", 
possuía tecnologia distintiva e presença consolidada na América do Sul, sendo, naquele momento, o único postulante com a cadeia de abastecimento integrada na sua totalidade, ou seja, com pleno domínio sob o ponto de vista tecnológico de todas as etapas de processo, desde a fabricação do polímero até a etapa final de dipping, diferentemente dos outros concorrentes.

O processo de negociação contratual entre as partes levou cerca de dois anos. Discussões sobre volumes mínimos de fornecimento, prazos contratuais e preços a serem praticados, localização das unidades a serem construídas pela Empresa "T", foram alguns dos assuntos que ocuparam as agendas dos executivos das duas empresas. Certamente, as recorrentes rodadas de negociação, marcadas por sucessivas situações de barganha estratégica, atuaram na direção da elevação dos custos de transação ex-ante incremento nos custos associados à coleta de informações e arranjos do acordo, por exemplo - contribuindo assim para a relativa demora de sua finalização. Por meio dos depoimentos colhidos ao longo da pesquisa, foi possível notar que situações de racionalidade limitada e oportunismo dos agentes - materializadas pela incapacidade de concepção de um contrato que otimizasse os benefícios mutuamente, e pelo desejo de cada parte, individualmente, tentar maximizar seus próprios interesses - contribuíram também para a emersão dos custos de transação $e x$ post, tendo em vista as situações conflituosas enfrentadas pelas partes após o início do contrato.

Solucionadas as pendências, sob o ponto de vista das negociações, o contrato foi efetivamente firmado em outubro de 1997, prevendo o início das operações da nova unidade para junho de 1999, em um projeto com orçamento ao redor de US\$ 15 milhões, arcado pela Empresa "T". Os termos contratuais previam que, a Empresa "P" manteria uma capacidade de tratamento de tecidos na ordem de $20 \%$, mediante a não-desativação de uma de suas unidades de dipping.

A nova unidade de dipping da Empresa “T”, construída em Camaçari-BA, foi liberada para a etapa de homologação e comissionamento em novembro de 1999, tendo seu início comercial um ano depois, em novembro de 2000. A escolha por Camaçari-BA, deveu-se sobretudo, pelo fato da Empresa "T" já possuir uma unidade de produção de fios e tecidos de reforço na localidade, diluindo assim os custos fixos relacionados à operação e à administração da nova unidade. Incentivos fiscais oferecidos pelo governo do Estado da Bahia foram importantes, porém não determinantes, segundo os dirigentes entrevistados. Naturalmente, a distância do Estado da Bahia em relação aos centros produtores de pneus, concentrados, sobretudo, na região Sudeste, foi objeto de questionamentos por parte da Empresa "P”, não inviabilizando, contudo, a escolha do estado nordestino.

\subsection{Possíveis razões para a defasagem da reconfiguração da cadeia à luz dos referenciaís teóricos observados}

Nesta seção aprofunda-se a discussão acerca das mudanças geradas pelo processo de desintegração vertical aqui analisado. Embora a unidade analítica adotada seja a transação em si (Williamson, 1985, 1991, 2004), neste caso, a de aquisição de tecido tratado, as conseqüências das condutas adotadas pelas empresas "P" e "T" repercutiram também em outros atores da cadeia, incluindo outros fornecedores de tecido e outros fabricantes de pneus, conforme será observado adiante.

\subsubsection{Especificidade de ativos, fornecedo- res locais e variáveis tecnológicas}

Retomando o argumento de Williamson (1985), pelo qual ativo específico é aquele que não pode ser facilmente reempregado, a não ser com perdas de valor, e fazendo sua ligação com a realidade do caso em estudo, verifica-se que tanto a unidade de dipping construída pela Empresa "T" - a qual apresenta a finalidade de tratar quimicamente tecidos para reforço de pneus fabricados por empresas que homologaram sua unidade - quanto seu produto, o tecido em si, que não pode ser reutilizado para outro fim, podem ser tipificados como ativos específicos.

Diante da presença de alta especificidade, são esperadas condutas orientadas no sentido da diminuição das incertezas, de forma a minimizar os custos de transação. A execução de investimentos em ativos específicos dedicados, ou seja, a princípio destinados à realização da transação com um único cliente em particular, e em ativos específicos físicos, voltados às instalações especializadas para a produção de um componente (Williamson, 1991), se torna exeqüível, preferencialmente, com a existência de um conjunto de garantias, que salvaguardem, de eventuais condutas oportunistas, a parte que realizou os investimentos, sobretudo quando tais inversões implicam o desembolso na casa das dezenas de milhões de dólares. $\mathrm{Na}$ relação empírica estudada, verificou-se que somente o estabelecimento de um contrato firmado por duas organizações de renome e, sobretudo, com reputação mútua construída ao longo de vários anos de relacionamento, foi capaz de diminuir as incertezas e, a reboque, os custos de transação envolvidos, possibilitando a desintegração vertical da atividade e, por conseqüência, viabilizando o redesenho da cadeia produtiva.

Pelo que pôde ser constatada nesta investigação, uma outra ramificação da dimensão especificidade de ativos impacta nas decisões de reconfiguração da cadeia de produção: a especificidade locacional, neste caso representada pela importância da proximidade de fornecedores locais, à medida que a proximidade entre os elos da mesma 
cadeia produtiva pode contribuir para a diminuição dos custos de transporte e inventário e, também, para a minimização dos riscos de falta de material.

O desenvolvimento deste argumento pode ser realizado mediante análise das condutas de outros dois fabricantes de pneus atuantes no Brasil, em que a questão da terceirização da etapa de tratamento apresenta distintos padrões de encaminhamento. As duas empresas entrevistadas, aqui denominadas "C" e "D", ambas multinacionais de grande porte, consideram o processo de dipping vital à performance do produto final - altamente estratégico, segundo os executivos entrevistados. Como é de praxe no setor, ambas as companhias desenvolveram, ao longo dos anos, tecnologias distintivas para a execução da etapa de tratamento químico de tecidos, principalmente no tocante à formulação da solução aquosa utilizada para a impregnação do tecido, o que, em certa medida, acaba por contribuir, também, para a elevação da especificidade dos ativos envolvidos, à medida que o tecido tratado para um fabricante de pneus, dificilmente pode ser utilizado por outro. Desta forma, é inegável que tal fato age como fator restritivo adicional à entrada de empresas de dipagem independentes, dificultando assim a desintegração vertical da atividade em análise.

Enquanto as discussões para a terceirização da etapa de dipping na Empresa "D" na América do Sul encontravam-se ainda em estágio embrionário, em meados de 2002, época de realização da última entrevista junto a um executivo da companhia, a Empresa "C" vinha sinalizando a intenção de executar a terceirização de sua unidade de dipping que, a exemplo das antigas unidades de tratamento da Empresa "P", também se encontravam tecnologicamente obsoletas, com mais de 30 anos de vida. Muito embora o tema da terceirização da unidade de dipping já tenha sido, no passado, pauta de diversas discussões internas na Empresa "C", fatores ligados à complexa logística de importação (fontes geradoras de incertezas), portanto, de custos de transação, e aspectos ligados à confiabilidade do fornecedor em termos de preço, prazo e qualidade, contribuíram para o não andamento do processo. Segundo um executivo entrevistado, a presença de fornecedores qualificados em nível local, que atendam aos tópicos acima, estaria estimulando a Empresa "C", a considerar a terceirização deste processo, evidenciando assim a externalidade positiva gerada pela conduta pioneira da empresa "P", a qual pode ser apropriada por outros atores do setor, em um fenômeno conhecido como "efeito-carona" (Azevedo, 1996).

Aspectos ligados à obsolescência tecnológica dos ativos envolvidos, do que pôde ser constatado na pesquisa empírica, também apresentam correlação com a decisão de desintegração vertical. Ocorre que, em função de unidades de dipping tecnologicamente obsoletas não serem capazes de conferir as propriedades necessárias ao alcance pleno das características desejadas pelo mercado, fazse necessário sua atualização tecnológica.

Entretanto, considerando-se que: a) os montantes envolvidos na substituição de unidades antigas por novas podem chegar a cifras de até US\$ 20 milhões; b) em função da diminuição das margens de lucro, os fundos disponíveis para novos investimentos estão escassos, devendo ser direcionados para aspectos relacionados à atividade fim da empresa; c) o negócio principal das indústrias de pneus é montar pneus, e não executar o tratamento químico de seus tecidos de reforço, conforme colocado unanimemente, por todos os executivos entrevistados; d) tanto a Empresa "P", que já optou pela terceirização, quanto a Empresa "C", em processo de análise de viabilidade, apresentavam unidades de dipping com mais de 20 anos de utilização; e e) a Empresa "D", que ainda não iniciou o processo de análise sobre a viabilidade da terceirização, possui uma unidade de dipping tecnologicamente atualizada; chega-se à constatação de que, para este processo, a obsolescência tecnológica das unidades atuais é um fator determinante para a decisão de terceirizar.

Em última instância, há indícios de que o investimento em ativos específicos tem papel preponderante nas decisões de reestruturação da cadeia.

\subsubsection{0 ambiente institucional}

Apesar do fato das unidades de dipping da Empresa "P", há algum tempo, já se encontrarem obsoletas sob o ponto de vista tecnológico - a sua unidade mais recente datava de 1976 -, observou-se que o interesse para a adoção da terceirização se iniciou por volta do ano de 1995 , portanto, após a introdução do Plano Real. No entanto, não foi observada, nesta pesquisa, qualquer influência de mudanças na matriz institucional brasileira pós-Plano Real, sobre a decisão de terceirizar o processo produtivo em estudo.

De acordo com o exposto durante a discussão do caso, a reputação mutuamente adquirida ao longo dos anos de relacionamento entre Empresas " $P$ " $e$ "T" em outros países, constitui-se na forma determinante de proteção a eventuais condutas auto-interessadas, regionalmente localizadas, corroborando o argumento teórico defendido por Dollinger et al. (1997), a respeito dos efeitos da reputação no relacionamento entre as empresas. Neste contexto, as cortes raramente são utilizadas, ficando a solução dos eventuais conflitos que venham a emergir restritas ao plano privado, em mecanismos conhecidos como private ordering (Azevedo, 1996). Desta forma, a despeito do sistema de garantia de contratos e da eficiência do setor judiciário brasileiro estarem aquém da realidade enfrentada palas duas empresas em suas operações nos países centrais, tais fatores não contribuíram para a demora, por 
parte da Empresa "P", na decisão de terceirizar suas unidades de tratamento químico de tecidos. Tampouco, tais fatores foram preponderantes na decisão da Empresa "T" de investir milhões de dólares em uma nova unidade de dipping para o atendimento das demandas das indústrias de pneus que operam no Brasil.

Ponderações acerca da dificuldade de realizar transações de importação no Brasil são freqüientes nos meios empresariais, segundo os entrevistados nesta pesquisa, quer seja por conta do complexo, burocrático e, sobretudo, custoso caminho da legislação brasileira; quer seja por conta da morosidade alfandegária, notadamente nos freqüentes períodos de "operação padrão" da Receita Federal. Tais fatores, não raro, desencorajam a utilização da via de importações para o atendimento das demandas internas, contribuindo diretamente para emersão dos custos de transação, no caso da inexistência de alternativas locais. Neste contexto, e com base nas discussões realizadas anteriormente a respeito do caso empírico, é pouco provável que as indústrias de pneus promovam a desintegração vertical de suas atividades de tratamento de tecidos, em favor de formas híbridas ou de mercado junto a fontes de suprimento baseadas no exterior, ainda que estas sejam atraentes sob o ponto de vista econômico, uma vez que pairam incertezas sobre a continuidade da transação nestes moldes.

Conforme observado, as decisões são orientadas a outra direção, ou seja, ao estímulo do ingresso de alternativas locais de suprimento, vis-à-vis a conduta adotada pela Empresa "P" ao tentar atrair parceiros de renome para atuarem localmente. No caso de não ser possível ou de não se conseguir atrair entrantes para este novo mercado, a tendência será a manutenção do status quo, ou seja, permanência da estrutura hierárquica, demonstrando-se assim a influência das instituições para elevação dos custos de transação.

Em função de não existirem organizações brasileiras com o domínio tecnológico necessário à execução do processo de dipping, sua introdução no país requer investimentos de origem externa. Dentro deste ambiente, as instituições podem ter papel positivo nas decisões de investimento, na forma de benefícios relacionados à infra-estrutura (terreno, estradas, etc.), incentivos fiscais, ou na forma de facilidades para aquisição de fundos em eventuais agências locais de fomento (por exemplo: BNDES, FINEP, Desenbahia, dentre outras).

Diante dos argumentos apresentados anteriormente se pode concluir que o ambiente institucional apresenta papel relevante nas decisões de reconfiguração da cadeia, a despeito do fato que, no caso empírico estudado, a ausência de um marco legal, que protegesse os agentes de condutas oportunistas, não tenha sido um fator chave na decisão de terceirizar.

\subsection{Algumas notas sobre o processo de execução contratual}

Com a desativação de $80 \%$ de sua capacidade de tratamento na América do Sul, a Empresa "P" teria que direcionar tecidos não-tratados provenientes de outros fornecedores para a nova unidade da Empresa "T", numa intrincada operação, tanto sob o ponto de vista fiscal quanto sob o aspecto logístico, gerando uma série de custos de transação ex-post, oriundos da racionalidade limitada dos agentes ex-ante. Como exemplo, tem-se, que em alguns casos, os fluxos de materiais não seguiam rotas de todo racionais, havendo situações em que o tecido nãotratado era enviado da unidade de um dos fornecedores de tecido situada em Buenos Aires-Argentina, via caminhão, para Camaçari-BA, onde seria tratado e enviado para ser calandrado em uma unidade da empresa "P" em Gravataí-RS, para, em seguida, ser despachado novamente, para que o pneu fosse montado em outra unidade da Empresa "P", também em Buenos Aires, aumentando o ciclo de processamento do produto e os estoques em processo envolvidos. Para que se tenha uma idéia da magnitude dos custos de transação ex-post, ocasionados por inadequações contratuais, visando evitar interrupções na produção de pneus nas unidades da Empresa "P," ao longo do ano de 2001 foram gastos, adicionalmente, cerca de US\$ 150 mil com transportes em regime de urgência - rodoviário e aéreo. Além disso emergiram, também, os custos de transação relacionados ao monitoramento das atividades e ao desgaste da relação entre as partes. Para maiores detalhes sobre os custos de transação ex-post nesta relação contratual, ver Cabral (2002).

Dado que a presença de ativos específicos implica dependência bilateral (Williamson, 1991), como forma de evitar o temido "dilema da dependência de um único fornecedor", a Empresa "P", além de manter uma pequena capacidade em termos de tratamento de tecidos de reforço, também estimulou, após a assinatura do contrato de terceirização com a Empresa "T", a construção de uma nova unidade de dipping com o outro player atuante no fornecimento de tecidos de reforço para a indústria de pneus. Esta nova unidade, localizada em Santo AndréSP, iniciou suas operações em meados de 2003. Com este tipo de conduta estratégica, a Empresa "P", além de se beneficiar futuramente nas negociações por meio do exercício de seu poder de barganha, novamente possibilitou a geração de externalidades positivas para os outros fabricantes de pneus, uma vez que uma fonte adicional e, mais importante, local, de matérias-primas passou a estar disponível. Com efeito, a empresa " $D$ ", no momento da confecção deste artigo, iniciava os testes para homologação da unidade de dipping do novo entrante.

Por meio da análise da Figura 3, observa-se que, antes de iniciado o processo de terceirização, a transação 
de aquisição de tecido tratado quimicamente, ou dipado, apresentava altos níveis de especificidade de ativos, representado por $k_{2}$, sobretudo pelo fato do consumo de tecido tratado, por parte das etapas subseqüentes de processo, serem, naquele momento, dependentes, em sua totalidade, das unidades de dipping internamente integradas.

A partir do momento em que a unidade da Empresa "T" passou a operar, pode-se afirmar que o nível de especificidade de ativos da transação moveu-se na direção do vetor $\beta$, deslocando-se de $k_{2}$ para $k^{*}$. Neste momento, a curva da estrutura de governança híbrida, representada por $X(k)$, passou a apresentar custos de transação menores em relação à curva da forma hierárquica, $H(k)$. A explicação, para referida redução nos níveis de especificidade, reside na difusão do padrão de tecnologia inerente à atividade. Com efeito, antes da entrada da Empresa "T", o conhecimento acerca das especificações do tecido tratado em termos de propriedades químicas e físicas adequadas - necessárias tanto ao andamento das próximas fases de produção quanto ao desempenho do produto final - estava restrito basicamente aos setores técnicos da Empresa "P". Tal processo de concentração de conhecimento, normalmente encarado à guisa de segredo industrial pelos fabricantes de pneus, contribuía para a elevação dos níveis de especificidade envolvidos ao redor desta transação. No caso dos fabricantes de pneus que ainda permanecem com estruturas verticalmente integradas, a alta especificidade ainda permanece, pois um tecido tratado para uma empresa de pneus, dificilmente pode ser utilizado por outro fabricante, conforme já mencionado anteriormente.

Não obstante o fato dos custos de transação da relação estarem sendo, até hoje, gradativamente reduzidos, por

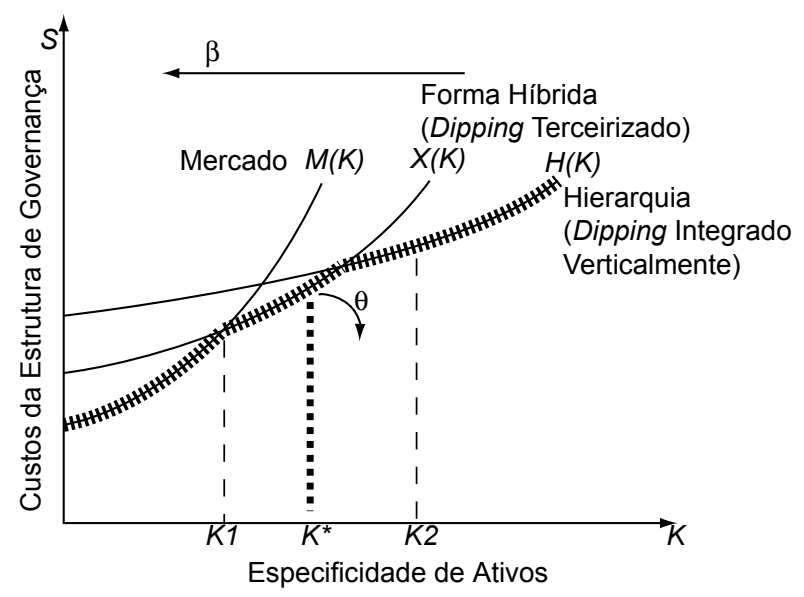

Figura 3. Estrutura de Governança em função da Especificidade de Ativos para a transação de aquisição de tecido tratado. Fonte: Desenvolvido a partir de Williamson (1996). conta do aumento da freqüência das transações, elevando assim o conhecimento que as partes possuem, uma em relação à outra, a Empresa "P", conforme observado anteriormente, estimulou a atração de mais um fornecedor para o mercado local, de forma a poder controlar, a seu critério, o grau de dependência bilateral. Analisando esta conduta à luz da Economia dos Custos de Transação, constata-se que tal ação deverá ter como efeito a acentuação da modificação dos níveis de especificidade de ativos $(k)$, na direção do vetor $\beta$ para um determinado valor $k$, tal que $k l<k<k^{*}$, dado que, com a entrada de um novo player, o padrão de tecnologia necessário à operação irá se difundir ainda mais.

Diante disso, é possível inferir que a viabilização do processo de reconfiguração da cadeia mediante a terceirização, somente tornou-se factível e economicamente viável por meio da adoção de abordagens de orientação estratégica realizadas endogenamente, fruto da dinâmica competitiva do setor, cuja estrutura de mercado se aproxima da concorrência oligopolística. Tais ações estratégicas, resultaram na redução da especificidade de ativos, o que possibilitou a mudança da estrutura de governança hierárquica em direção a formas contratuais híbridas.

\section{Considerações finais}

De acordo com o debatido, o presente estudo permite a realização de uma série de reflexões acerca dos fatores envolvidos no processo de reconfiguração da cadeia, a partir da terceirização de etapas centrais do processo produtivo de uma organização, à medida que aporta alguns elementos analíticos pouco explorados nos meios empresariais quando da elaboração de estratégias visando à revisão das fronteiras organizacionais. Dentre estes, destaca-se a Economia dos Custos de Transação, incluindo seus pressupostos básicos - racionalidade limitada e oportunismo - e suas dimensões analíticas: especificidade de ativos, freqüência e incerteza, com destaque para a importância da matriz institucional nas decisões de investimento, sobretudo em ambientes nos quais os sistemas de garantia e execução contratual não são de todo eficientes.

Em adição às "já consagradas" justificativas para a dinâmica do processo de reconfiguração da cadeia via terceirização (transformação de custos fixos em variáveis e foco nas competências essenciais), as principais constatações deste artigo em relação a este fenômeno, são sintetizadas abaixo:

- Importância da presença de fornecedores locais e de ações estratégicas para reconfiguração da cadeia. quer seja por iniciativa das empresas que vislumbram seguir os rumos da terceirização, quer seja por parte de companhias que almejam expandir suas atividades via incorporação de processos localizados no sentido 
downstream de sua cadeia de atuação. Além disso, por meio de ações estratégicas, os atores ao mesmo tempo em que decidem alterar a estrutura de governança da transação podem também, dentro de uma perspectiva dinâmica, manejar o grau de dependência bilateral imposto pela presença de ativos específicos. Neste sentido é emblemática a conduta da empresa "P", ao atrair fornecedores alternativos, depois de firmado o contrato com a Empresa " $T$ ";

- Papel das matrizes institucionais na dinâmica de terceirização. Muito embora o ambiente institucional brasileiro não tenha sido totalmente impeditivo nas decisões de reestruturação da cadeia de produção abordadas neste artigo, visto que, por exemplo, os atores do caso analisado normalmente recorrem a soluções do tipo private ordering para resolução de suas pendências, constatou-se que as instituições brasileiras ocupam uma posição relevante na análise, à medida que, dentre outros fatores, podem dificultar as transações de aquisição via importações. Neste sentido, para minimização dos custos de transação, verifica-se a relevância da presença de fornecedores de reputação previamente conhecida operando localmente (Dyer, 1997; Dollinger et al., 1997). Tais fatos evidenciam a influência das instituições, formais e informais, no que se refere à limitação das escolhas dos indivíduos e das organizações (North, 1990);

- Influência da dimensão especificidade de ativos nas decisões estratégicas envolvendo reconfiguração da cadeia de abastecimento. No caso em estudo, a dificuldade na difusão do padrão de tecnologia adotado, normalmente de propriedade das empresas de pneus, e a importância estratégica do processo em análise no desempenho do produto final atuam na direção da elevação do nível de especificidade de ativos, tendo contribuído para o atraso relativo da decisão de desintegração vertical no Brasil. Fruto da dinâmica competitiva do setor, a mudança da estrutura organizacional, outrora vigente, ape- nas se tornou possível por força de ações estratégicas no sentido de diminuir o grau de especificidade dos ativos e da utilização concomitante de mecanismos de coordenação objetivos (contratos) e subjetivos (reputação); e

- Caráter irreversível das mudanças observadas na cadeia de produção de pneus no Brasil. A partir da criação das condições que viabilizaram a reconfiguração da cadeia de produção, fomentadas pelas Empresas "P" e "T", ao que tudo indica, as empresas de pneus no Brasil tenderão a adotar a desintegração vertical de suas unidades de dipping, principalmente, após a construção de novas unidades por parte de fornecedores na região. Por outro lado, para os fornecedores de tecido tratado, a integração vertical faz-se necessária, para promover rotas seguras de escoamento dos produtos manufaturados no sentido downstream de sua cadeia.

Dentro dos limites estabelecidos para a extrapolação dos resultados deste artigo, válidos somente para o caso analisado, espera-se também que este trabalho possa servir como fonte de reflexão para outros relacionamentos dentro do oligopsônio estudado, sobretudo quando da tomada de novas decisões sobre futuros processos de reconfiguração da cadeia de produção que as organizações venham a experimentar, seja via terceirização ou integração vertical, em situações de dependência bilateral impostas por ativos específicos.

Acredita-se, por fim, que a realização de estudos empíricos adicionais, envolvendo abordagens econométricas que possibilitem a mensuração dos custos de transação, além de contribuir para o desenvolvimento de trabalhos acadêmicos nos campos da Economia, Administração e Engenharia de Produção possibilitará, também, que as potencialidades dos ferramentais propiciados pela Economia dos Custos de Transação sejam difundidas em maior escala nos meios empresariais, ganhando relevância em processos decisórios relacionados às estratégias de definição das fronteiras organizacionais.

\section{Referências Bibliográficas}

ALLEN, D. W.; LUECK, D. Agricultural Contracts. In: MÉNARD, C.; SHIRLEY, M. (eds.): Handbook of New Institutional Economics. Kluwer Academic Publishers, 2004 (no prelo), p. 465-490.

AZEVEDO, P. F. Integração Vertical e Barganha. 1996. 221 p.. (Tese de Doutorado) Departamento de Economia FEA/USP, São Paulo, 1996.

BARTHELEMY, J.; QUELIN, B. V. Contractual Agreements and Outsourcing: A Transaction-Cost Analysis. In: ANNUAL CONFERENCE OF THE INTERNATIONAL SOCIETY FOR NEW INSTITUTIONAL ECONOMICS, 4., sep, 2000, Turbigen (Germany).Anais... 30 p.
CABRAL, Sandro. Terceirização de Processos Industriais sob a Ótica da Economia dos Custos de Transação. 2002. 99 p.. Dissertação (Mestrado em Administração) Núcleo de Pós-Graduação em Administração. Escola de Administração - UFBA, Salvador - BA, 2002.

CARMO, L. F. R. S.; HAMACHER, S. A evolução da cadeia de suprimentos da indústria automobilística no Brasil. In: Revista de Administração Contemporânea, v. 5, n. 2, p. 201-220, 2001.

COASE, R. The Nature of the Firm. (1937). In: The firm, the Market and the Law. Chicago: University of Chicago Press, 1988. 
DOLLINGER, M. J.; GOLDEN, P. A.; SAXTON, T. The Effect of Reputation on the decision to joint-venture. Strategic Management Journal, v. 18, n. 2, p. 127-140, 1997.

DYER, J. H. Effective Interfirm Collaboration: How Firms Miniminize Transaction Costs and Maximize Transaction Value. Strategic Management Journal, v. 18, n. 7, p. 535-556, 1997.

FARINA, E.; ZYLBERSZTAJN, D. Competitividade e Organização das Cadeias Agroindustriais. Projeto Segurança Alimentar. Departamento de Engenharia de Produção - UFSCar, São Carlos, 1995 (mímeo).

FARINA, E.; AZEVEDO, P. F.; SAES, M. S. Competitividade, Mercado, Estado e Organizações. São Paulo: Ed. Singular, 1997, $286 \mathrm{p}$.

GUTWALD, P. M. Strategic Sourcing and Technology Supply-Chains. Massachusetts, MIT, 1996 (Master Thesis), $93 \mathrm{p}$.

MALHORTA, N. Pesquisa de Marketing: Uma orientação aplicada. Porto Alegre: Bookman, 3. ed., 2001, p. 161-166

MÉNARD, C. The Economics of Hybrid Organizations. In: Journal of Institutional and Theoretical Economics. 2004, p. 1-32.

NORTH, D. Understanding Institutions. In: Ménard, C. (ed.). Institutions, Contracts and Organizations: perspectives from New Institutional Economics. Cambridge: Edward Elgar, 2000, p. 7-10.

Institutions, Institutional Change and Economic Performance. Cambridge University Press, 1990, 152 p.
QUINTÃO, R.; CARVALHO, R. Q. Relações Cliente/Fornecedor, Governança e Desenvolvimento Tecnológico na Cadeia Automotiva Brasileira. In. ENANPAD, 26., 2002, Salvador - BA. Anais... Rio de Janeiro: ANPAD, 2002. CD-ROM.

REZENDE, W. Terceirização: A Integração Acabou?. In: Revista de Administração de Empresas - FGV/SP. São Paulo, v. 37, n. 4, p.6-15, out.-dez. 1997.

ROESCH, S. Projetos de Estágio e de Pesquisa em Administração. São Paulo: Atlas, 1999, p. 195-279.

Proposta para a Dissertação de Mestrado Profissional. Londres, 2001, 13 p. (mímeo)

SHIRLEY, M. What Does Institutional Economics tell us about Development. In: Ronald Coase Institute Workshop on Institutional Analysis, USP, São Paulo, 2003.

WILLIAMSON, O. E. Operationalizing Transaction Cost Economics. In: Ronald Coase Institute Workshop on Institutional Analysis. Tucson-AZ, 2004.

The Mechanisms of Governance. Oxford: Oxford University Press, 1996.

Comparative Economic Organization: The Analysis of Discrete Structure Alternatives. Administrative Science Quartely, v. 36, p. 269-296, 1991.

The Economic Institutions of Capitalism: Firms, Markets, Relational Contracting. New York, The Free Press, 1985, $450 \mathrm{p}$.

WOMACK, J.; JONES, D. A Mentalidade Enxuta nas Empresas. 7. ed. Rio de Janeiro: Ed. Campus, 1998. 428 p.

YIN, R. K. Case Study Research: Design and Methods. 2. ed. Sage Publications, 1994, 171 p.

\title{
AN ANALYSIS OF THE RECONFIGURATION OF BRAZIL'S TIRE PRODUCTION CHAIN APPLYING THE TRANSACTION COST ECONOMICS APPROACH
}

\begin{abstract}
This paper discusses the reconfiguration of Brazil's tire production chain resulting from the pioneer outsourcing and vertical disintegration of the tire cord treatment units, also known as dipping units. A case study of the contractual relationship between two large multinational corporations is used as a methodological strategy. Analyses are made of the process of contractual adaptation and of the factors that may have contributed to delay the decision to restructure the tire production chain in Brazil. The Transaction Cost Economics approach was chosen as the theoretical framework, mainly due to its analytical capacity regarding the limits of action of firms or organizational networks. The empirical findings indicate the importance of specialized local suppliers as a critical factor in the restructuring of the supply chain through outsourcing strategies. The institutional environment, both formal and informal, is as relevant to the contractual process as it is to the decision-making involved in the definition of new organizational boundaries.
\end{abstract}

Keywords: supply chain management, outsourcing, transaction costs, asset specificity, institutional environment. 